\title{
BUSINESS CYCLES IN LATIN AMERICAN ECONOMY: I950-2007
}

\author{
Mosar Leandro Ness, Igor Alexandre Clemente de Morais, Angélica Massuquetti
}

\begin{abstract}
This article looks for the existence of common cycles in Latin America between 1950 and 2007. In this study, we used the technique of changing the Markovian regime, which in addition to univariate and multivariate formulations were tested bivariate arrangements. The main results indicate that it is possible to characterize the periods of growth and recessions in Argentina, Brazil, Chile and Mexico, especially in the two oil shocks in the beginning and the end of the 1970s; the crisis of balance of payments; and the problems of relative prices. Despite the existence of causality, bivariate models were tested between Argentina and Brazil, Chile and Mexico. The results suggest that smoothing of cycles, and the existence of movements of adjustment of economies to exogenous shocks that disrupted its dynamics of growth. It was also possible to identify differences in the speed of cyclical adjustment in each economy.
\end{abstract}

Key-words: Business Cycles; Latin American Economy; Markov Models.

\section{Resumo}

Esse artigo tem como objetivo avaliar a existência de ciclos comuns na América Latina entre 1950 e 2007. Nesse estudo, foi utilizada a técnica de mudança de regime Markoviano, que além das formulações univariadas e multivariadas foi testado arranjos bivariados. Os principais resultados indicam que é possível caracterizar os períodos de crescimento e recessão na Argentina, Brasil, Chile e México, especialmente nos dois choques do petróleo no início e fim dos anos 1970; na crise do Balanço de Pagamentos; e dos problemas de preços relativos. Devido à existência de causalidade foram testados modelos bivariados entre Argentina e Brasil, Chile e México. Os resultados sugerem que a existência de movimentos de ajuste das economias a choques exógenos interromperam a dinâmica dos ciclos de crescimento. Também foi possível identificar diferenças na velocidade do ajuste cíclico em cada economia.

Palavras-chave: Ciclo econômico; Economia Latino-americana; Modelo de Markov. 


\section{INTRODUCTION}

Over the past 60 years the world economy experienced an intense process of transformation in its institutional structures and production. During this period, economic systems disappeared, a new international economic order emerged with the intensification of the globalization process, and countries began to live with moments of crisis and expansion with different characteristics of earlier times, see Kose et al. (2003, 2005).

Burns and Mitchel (1946) were the pioneers in the interest of the international literature on business cycles, complemented with the use of more elaborate statistical techniques, as Bry and Boschan (1971), and followed by several other studies, see Stock and Watson (1988, 1989, 1991, 1993) and Hamilton (1989). Some of the features related to the cyclical behavior of univariated and multivariated series such as the asymmetry, frequency, intensity, duration, co-movements and the dynamic common factors, are widely studied. Beyond these stylized facts, it is important to know the turning points of the cycles. That is, the peaks and troughs of economic activity in each economy. Several studies try to capture the common factors to several countries or regions and the construction of leading, lagged and coincident indicators, see Zarnowitz (1996) and Chauvet and Morais (2008).

Most studies related to business cycle approach use industrialized economies data, in particular the G7 countries. Overall, the results indicate a reduction in volatility and, thus, a smoothing of the behavior of economic cycles. In relation to the economic environment, it was observed that the influence of international shocks decreased during 1980 compared to 1990 , which was found in the 1960s. The reason for this fact lies in the increased volume of trade and integration between the most industrialized countries. Some studies showed that increasing the volume of intra-regional trade, especially in the form of intra-industry, was an important factor to explain the degree of synchrony in the cycles, particularly in Asia and Europe, see Shin and Wang (2003) and Böwer and Guillemineau (2006).

If on one hand there is harmonization in terms of the behavior of the economies of the G7, on the other hand, the impact of structural shocks has demonstrated an ability to spread quickly those effects in all other economies, causing disturbances of high intensity and fluctuations in economic systems, see Kose et al. (2005). The integration between developed and emerging countries intensified since 2001, it also raised the idea of searching the cyclical movements in other regions, see Mendoza (1995), Correa (2003), Correa and Hilbrecht (2004) and Kose et al. (2008) that indicate the existence of similar features on the movement of economic aggregates.

Another important point is the identification of external factors that are common to these countries; and, if a shock in one country has the power to affect the cycle in the other. This observation may help understand how the nature of external shocks affects the cycle so common among the different economies. Among the reasons given for studying the existence of common regional factors, is the fact that the position is geographically close, it helps to increase the likelihood of being affected by regional shocks, such as those related to climate.

In a study on the behavior of four Latin American countries: Brazil, Argentina, Chile and Mexico, Aiolfi et al. (2006) used a Bayesian Dynamic Factor Model as data for more than one hundred years. Estimate were made considering different periods, as the stage prior to World Wars, between the wars and post-war, which is fragmented in the period with the agreement of Bretton Woods and post-liberalization of the exchange. The results indicated a pro-cyclical behavior of output, wages and foreign trade. On the other hand, the countercyclical behavior was observed for a highly volatile fixed investment and inflation among the selected countries.

The results found by the author reveal peculiarities of Latin America as a common response to large external shocks of the 1970's and early 1980 's, as increasing oil prices, the highest level of international interest rates and recessions in developed countries. The increase in financial flows and trade, as a result of a larger process of integrating the region with other countries in the wake of major institutional changes, is also an element of emphasis in this period.

The economic history of Latin America shows that since the early 1980's, several structural reforms and institutional policies were implemented in several countries. In this case focused on Chile and Mexico, which intensified the process of trade integration, promoted changes in the domestic financial market and allowed the flow of capital; in Brazil, with the monetary stabilization of the mid-1990's, a greater transparency in data public sector among others. Despite advances, there are times that it was possible to identify some political backward, particularly in Argentina with the 
default of debt in the early 2000's.

Generally, it can also be noted that in recent years a reduction in volatility of economic cycles in the region. This occurs even without fiscal and monetary policies coordination. The role played by domestic institutions in the conduction of economic policy is one of the factors that are characterized as a pro-cyclical, sometimes acting as an inducer of higher, sometimes with less volatility in cycles.

The main contribution of this paper is to identify the cyclical characteristics of four major Latin American countries: Argentina, Brazil, Chile and Mexico over the period 1950 to 2007. Besides the observation of stylized facts relating, such as asymmetry, duration and intensity that can be evaluated under the focus of models of change in Markov Switching Models, other secondary objectives are achieved. In this case, the turning points are specified. Another interesting result is the use of multivariate models that can confirm the existence of a common cycle in the region, it shows that the response to such external shocks has the same magnitude and dynamics in each one. In addition to this introduction, this paper has five sections. In section two, a brief review of theoretical models with a change of regime and its use in the literature, which investigates the business cycle. In section three, there are the results of testing for univariate models. In section four, there are the multivariate results and, finally in section five there are the conclusions and suggestions for future research.

\section{METHODOLOGY}

The study of the economic cycles is a work of observation of the effects of fluctuations on the economic variables, such as measurement, analysis, and forecasting. This paper follows the proposal from Hamilton (1989) that uses Markov Switching Models to characterize the cyclical movements in univariate time series. Subsequently, in the multivariate models we use Krolzig (1996). In its basic formulation, the autoregressive vector model (VAR) considers the variables of symmetry, preserving its independence. However, for the instrumental analysis of VAR, they become useful for the formulation of economic models with a better structure. Consider that the vector of size $k$ is generated by a process of order $p$ :

$y_{t}=A_{0}+A_{1} y_{t-1}+\ldots . .+A_{p} y_{t-p}+\varepsilon_{t}$ with $t=1, \ldots . ., T$, and $A_{0}$ is a vector of $k$ constants, $A_{i}$ are matrix of $[k x k]$ with $k^{2}$ coefficients, and that is estimated $k+p k^{2}$ parameters. Finally, $\varepsilon_{t} \sim N I D(0, \Sigma)$ and $E\left(\varepsilon_{t} \varepsilon_{t}{ }^{\prime}\right)=\Sigma$ are the variancecovariance matrix that is positive-defined, nonsingular and time-independent.

Assuming the existence of $\mathrm{k}$ states, the probabilities of transition between them $P=\left[p_{j}\right] \in M(k x k)$ can be represented by a matrix of transition probability as:

$$
P=\left[\begin{array}{cccc}
p_{11} & p_{21} & . . & p_{k 1} \\
p_{12} & p_{22} & . . & p_{k 2} \\
: & : & : & : \\
p_{1 k} & p_{2 k} & . . & p_{k k}
\end{array}\right]
$$

where $\sum_{j=1}^{k} p_{i j}=1_{i=1,2, \ldots, k,} p_{i j} \geq 0, i, j=1,2, \ldots \ldots, k$, and the vector of Markov transition probability are $P=\left(P_{11}, \ldots P_{k k}\right)^{\prime},\left(k^{2} x 1\right)$. In general, the MS-VAR models are considered a generalization of finite linear autoregressive order in a vector of time series $y_{t}=\left(y_{1 t}, \ldots, y_{m t}\right)^{\prime} m$ order, $t=1, \ldots, T$ :

$y_{t}=A_{0}+A_{1}\left(y_{t-1}\right)+\ldots . .+A_{p}\left(y_{t-p}\right)+\varepsilon_{t}$

with matrix of coefficients $A i$ ( $m x m$ ), $\varepsilon_{t} \sim N I D(0, \Sigma)$. In this case the parameters depend on a latent variable not observed:

$$
y_{t}=A_{0}\left(s_{t}\right)+A_{1}\left(s_{t}\right)\left(y_{t-1}\right)+\ldots . . .+A_{p}\left(s_{t}\right)\left(y_{t-p}\right)+\varepsilon_{t}
$$

where $\varepsilon_{t} \sim \operatorname{NID}\left(0, \Sigma_{s_{t}}\right)$. Subtracting $y_{t-1}$ from (2.3) we see vector error correction model:

$\Delta y_{t}=A_{0}\left(s_{t}\right)+\alpha y_{t-p}+\sum_{i=1}^{p-1} B_{i} \Delta y_{t-i}+\varepsilon_{t}$

where $B_{i}=-\left(I_{k}-\sum_{j=1}^{i} A_{j}\right) \quad e^{\alpha=I_{k}-\sum_{j=1}^{p} A_{j}=A(1)}$. The equation (2.4) is denominated MSCI (k, r)-VAR(p), or vector autoregressive of order $\mathrm{p}$ with a $\mathrm{k}$ states and $r$ cointegration rank. In addition to this formulation, another way would be to consider that there is a change in regime in the growth rate $\mu_{s_{t}}$ :

$$
\begin{aligned}
& \Delta y_{t}-\mu\left(s_{t}\right)=\alpha\left(\beta^{\prime} y_{t-p}-\delta-\gamma t\right)+A_{1}\left(\Delta y_{t-1}-\mu\left(s_{t}\right)+\ldots\right. \\
& \ldots+A_{p}\left(\Delta y_{t-p}-\mu\left(s_{t}\right)+\varepsilon_{t}\right.
\end{aligned}
$$


where $\beta^{\prime} y_{t-p}-\delta-\not t_{t}$ determines the long term equilibrium. A third possibility is considering a change in $\delta\left(s_{t}\right)$

$$
\begin{aligned}
& \Delta y_{t}-\mu=\alpha\left(\beta^{\prime} y_{t-p}-\delta\left(s_{t}\right)-\gamma t\right)+A_{1}\left(\Delta y_{t-1}-\mu\right)+\ldots \\
& \ldots+A_{p}\left(\Delta y_{t-p}-\mu\right)+\varepsilon_{t}
\end{aligned}
$$

or in the mean:

$$
\begin{aligned}
& \Delta y_{t}-\mu\left(s_{t}\right)=\alpha\left(\beta^{\prime} y_{t-p}-\delta(s)_{t}-\gamma t\right)+A_{1}\left(\Delta y_{t-1}-\mu\left(s_{t}\right)\right. \\
& +\ldots . .+A_{p}\left(\Delta y_{t-p}-\mu\left(s_{t}\right)+\varepsilon_{t}\right.
\end{aligned}
$$

A more detailed discussion of the methods of estimation, the procedure of choice for models of switching regime, specific tests and univariate and multivariate applications, can be seen in Clements et al. (1999, 2001), Chauvet (1998), Chauvet and Potter (2000), Chauvet and Morais (2008), Diebold et al. (1994), Filardo (1994), Filardo and Gordon (1998), Garcia (1998), Hansen (1992), Hamilton (1989, 1991, 1996), Hamilton and Susmel (1994), Kim and Nelson (2000), Krolzig (1996, 1997) and Zarnowitz (1996).

\section{UNIVARIATE MODELS}

The series of data used here are the gross domestic product in dollars at constant prices (index numbers base $2000=100$ ), from 1950 to 2007 . The set of figures 1 to 4 presents the behavior of these series in level and first difference ${ }^{1}$.

Figure 1: Argentina GDP

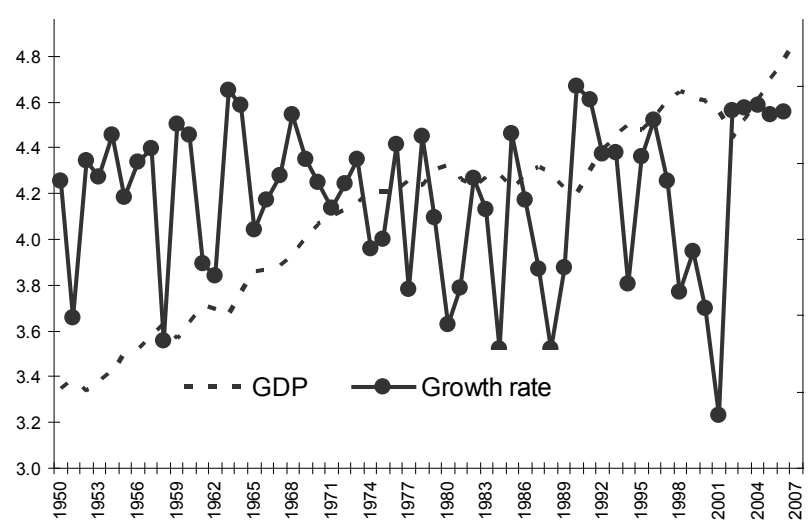

Figure 2: Brazil GDP

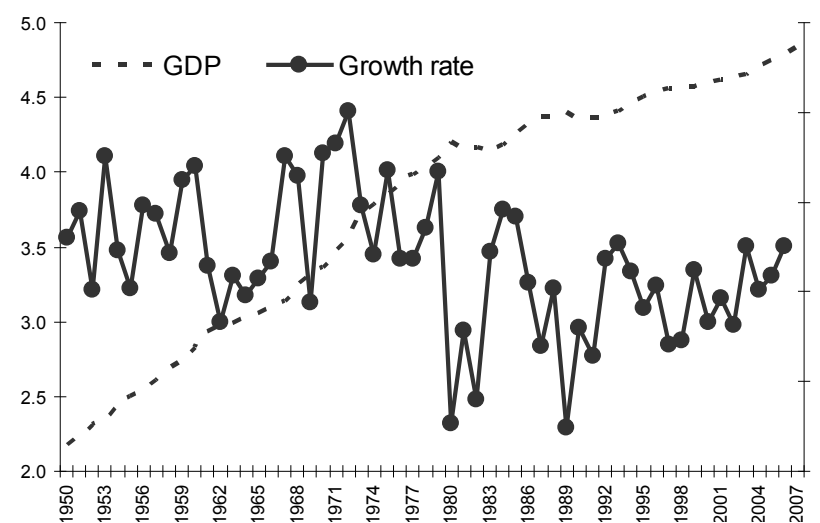

Source: Worldbank. (2008). Expressed in dollars and deflated by the implicit deflator of each economy.

Based in Hamilton (1989) and Krolzig (1997), we estimated models with two regimes, where $s_{t}=1$ indicates recession periods, and $s_{t}=2$ growth. We used models with switching in mean MSM (k)-AR(p), intercept term, MSI(K)-AR(p), autoregressive and heteroskedasticity. To select models and lags we used Akaike (AIC), Hanna-Quinn (HQ) and Schwartz (SC). This was complemented with the Likelihood Ratio tests. First, models as MS(2)-AR(4) are reduced in each step. Table 1 shows the best results for the univariate models following these criteria.

Figure 3: Chile GDP

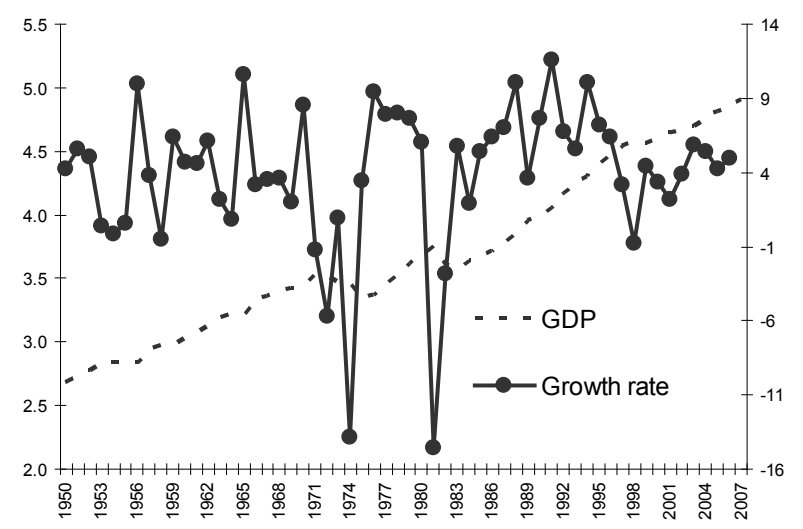

\footnotetext{
${ }^{1}$ The unit root tests indicated that the series in first difference are stationary.
} 
Figure 4: Mexico GDP

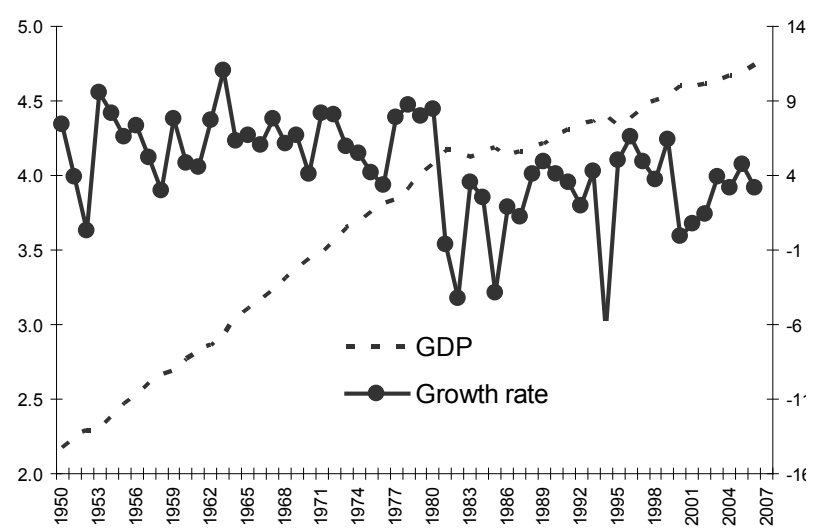

Source: Worldbank. (2008). Expressed in dollars and deflated by the implicit deflator of each economy.

A visual inspection identifies that there are some characteristics. Firstly, in the period used occurred several external common shocks in the countries, especially in the beginning and the end of the 70's, with the increase in oil prices. It caused cyclical waves in several countries in the world. In Chile, the effects were more pronounced. GDP shrink of about $13 \%$ in 1974 and 14\% in 1982. However, it was the international crisis of the early 1980's, related to the 2 nd oil shock, which had the power to put the four countries in the years following the downturn.

Table 1: Univariate models

\begin{tabular}{|c|c|c|c|c|c|c|c|}
\hline & Models & $\mu_{1}$ & $\mu_{2}$ & $p_{11}$ & $p_{2}$ & $D_{1}$ & $D_{2}$ \\
\hline Argentina & $\begin{array}{c}\mathrm{MSM}(2) \\
\mathrm{AR}(0)\end{array}$ & -3.74 & 5.60 & 0.408 & 0.733 & 1.69 & 3.75 \\
\hline Brazil & $\begin{array}{l}\text { MSM(2)- } \\
\text { AR(0) }\end{array}$ & 2.45 & 6.72 & 1.00 & 0.973 & 26.44 & 30.54 \\
\hline Chile & $\begin{array}{l}\text { MSI(2)- } \\
\text { AR(1) }\end{array}$ & -14.89 & 3.65 & 0.00 & 0.962 & 1.00 & 26.57 \\
\hline Mexico & $\begin{array}{l}\text { MSIH(2)- } \\
\text { AR(4) }\end{array}$ & -5.46 & 5.16 & 0.177 & 0.919 & 1.22 & 12.44 \\
\hline
\end{tabular}

Note: $\mu_{1}$ is GDP growth rate in recession phase and $\mu_{2}$ in the growth phase. $D_{1}$ and $D_{2}$ are cycle durations in regime 1 and 2. $p_{11}$ is the transition probability of regime 1 to regime 1 and $p_{22}$ is the transition probability of regime 2 to 2 .

Specifically in the case of Argentina the oscillations observed in the product may be related to events of political and economic driving with proposals that do not have to respond to external shocks. From 1946 with the beginning of the Perón government, there was a change in economic policy, similar to the Brazilian case of import substitution program. However, the strong expansion of domestic activity resulted in increasing demand for inputs in the domestic market. This situation could only be maintained with the generation of foreign currency. As the industry was still incipient the crises in balance of payment were imminent in Argentina over the years 50 and 60, implicating in a very volatile process of growth.

From 1980 the probability of recession has intensified in the country. In the early years of this decade, increases in international interest rates resulted in more payment of foreign debt, resulting in new crisis in the balance of payments in Argentina. A new economic model is adopted at the beginning of the next decade. In response to the hyperinflation process that has lasted for several years, the Argentine government adopts a program of liberalization of the economy. Among various measures adopted at that time, one of the most important was the use of the currency board, coupled with the Argentine peso to the dollar at parity, 1 by 1 . The positive results showed up immediately, and the country followed with longer periods of growth. This long cycle was interrupted after the crisis in the second half of the 90's that have discussed the exchange model. After the Mexican crisis, Asian economies, Russia and Brazil, Argentina was forced to change its economic policy in 2001. The movements of the probabilities associated with Argentina's economy can be seen in figure 5 .

The alternation in the dynamics of growth of the country in the post-Second World War, with successive changes of phases of expansion and recession, were captured by the switching model. This also indicates that the average growth rate of the economy, in regime 1 - recession, is $-3.74 \%$. This result confirms that the above effects of shocks on the country were deep in that period. The parameter that measures the rate of growth, although 
significant, is lower than that found by Correa (2003), who studied the economy of Argentina in the period 1900 to 2000 , based on annual data. Moreover, when Argentina's economy was in a regime of growth, the average rate is $5.60 \%$ per year. A different result was found by Correa (2003).

Figure 5: Probabilities of regime $1 \mathrm{MSM}(2)-\mathrm{AR}(0)$ - Argentina (1950 to 2007)

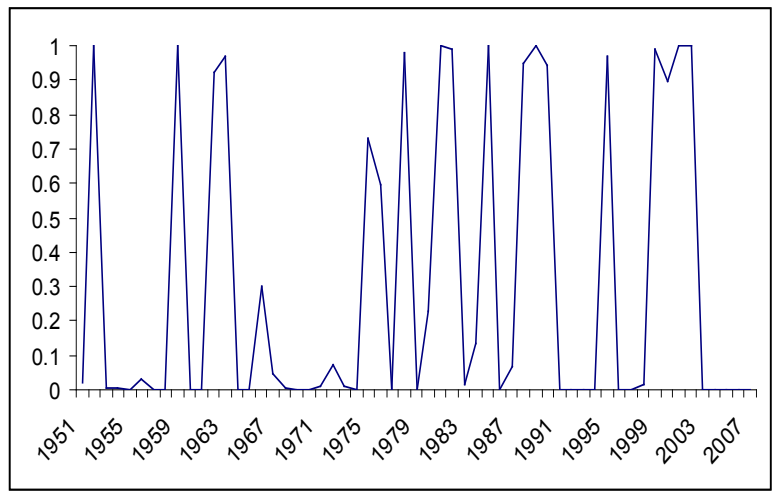

The Brazilian case showed that in periods of recession (regime 1), the economy grows at an average rate of $2.45 \%$ per annum. This result is very different than compared to results found for other countries. And, states that in this period, the recessions in Brazil were not characterized by negative rates, but by a process of growth less pronounced. This result was higher than that calculated by Correa (2003). A hypothesis that can explain this behavior is the fact that the process of Brazilian development was characterized by high growth in the post-war. Already in the growth regime the average rate is $6.72 \%$. This result is slightly lower than that reported by Correa (2003).

The matrix of probability of transition to Brazil indicates that if the economy is in recession or growing, the probability of switching $\left(p_{\mathrm{R}}, p_{2}\right)$ is very small. However, another reason for these numbers is the very dynamic growth of Brazil. In the period prior to 1980 the country was marked by a more intense economic activity, particularly between 1958 and 1960. Later, the Brazilian economic miracle led to a period of strong growth between 1969 and 1973. This was interrupted by the oil crisis that marks the turning point. This exogenous shock has two sources: first, it was a substantial increase in interest rate in the U.S. and second, a further increase in oil prices on the international market. As in Argentina, the greater need for payment of interest with the debt created imbalances in the current account, such enhanced by higher spending on imported oil.

The Government's attempts to adjust the balance of payments have achieved the purpose of contributing to the disruption of internal economic system. Of course the country had to abandon the growth model used so far. The 14 years marked heterodox frustrated attempts to stabilize the economy and put it into a new growth model, which is only installed in a consistent manner with the implementation of the Real Plan in 1994. Thus, in this period, even growing at average rates lower, the biggest benefit has been the lowest level of fluctuation growth. This will, ultimately, support a process of structural breaks in the series.

The exchange rate regime was one of the most important strategic of the Real Plan in the early years. The most benefit of controlling the exchange rate was the fall of domestic prices. However, trying to keep the exchange rate artificially overvalued, tried to make the economy vulnerable to currency crises and speculative shocks. The financial crisis of the 90s had its origin in four different aspects that interact with each other, ultimately creating the conditions for a speculative attack to the Brazilian economy: i) weakening of macroeconomic fundamentals, ii) multiple imbalance; iii) spillover effects between countries; iv) conditions to financial vulnerability. Thus, after the economic problems in other emerging countries, Brazil changes the exchange rate regime in 1999.

The first years follow the Augusto Pinochet government in 1973, resulted in a troubled macroeconomic scenario. However, in the end of the 1970's various institutional reforms took place and, in addition to the reduction of external vulnerability, the government managed to produce economic stability. Since then, Chile has entered into a long and pronounced growth. On the other hand, social policies implemented in the following years, like the employment, contributed to a distribution of wealth and the per capita income growing quickly. In constant prices, per capita income was three times higher during this period.

However, since then, the average growth of the Chilean economy systematically decreased: in 1990 was $6.0 \%$ per year. Since the decade of 2000 that number fell to just over $4.0 \%$ a year. Simonovska et al. (2008) makes an analysis of cyclical movements in that period. The reasons for the reduction of average rates can be attributed to a stage in which structural reforms will have an impact in declining marginal product. Elsewhere, 
it became evident the need to adapt the Chilean economy to interact in a context of global competition, and to create conditions to resist shocks of short and long term.

Simonovska et al. (2008) suggests that productivity in the labor market was the variable that best explained the volatility of the Chilean economic cycles over the period of 1998 to 2007. Moreover, investment only built a behavior according to expected in recent years, revealing, thus, the slow process of adjustment to structural reforms of the economy. In terms of prediction of government policies, it was observed that the rigidity in the labor market and expansion of the credit markets should be the two points to be addressed in order to smooth the volatility of economic cycles in the future.

These characteristics were captured in the model estimated to Chile. In periods of recession, the average growth rate is $-14.89 \%$, indicating that these were very pronounced. Furthermore, the parameter shows that, despite the Chilean economy over the period experienced a vigorous process of restructuring, they had a profound crisis. Otherwise, in the growth periods the rate is around $3.65 \%$. This result indicates that, although these are not so significant, it lasts for larger intervals. Even as Simonovska et al. (2008) introduced liberalizing reforms in the Chilean economy during the 80's managed to bring the positive effect to the GDP growth, in terms of rate and stabilization.

The results of the matrix of probabilities of transition, where the economy is in recession or growing, the probability of switching of regime is very small. Another interesting point is that when the country is in a recession, there is a high probability of moving to a regime of growth. These results show that although the parameter of the recessionary period is very pronounced, its duration is very short and that growth in Chile is stable over a period of time.

Mexico had also important political changes between the years of 1970 and 1990. The cyclical fluctuations in these periods were characterized by the exchange rate control, market distortions and external factors, see Santos (2002). It is true that Mexico between 1994 and 1995 had to implement solid and consistent macroeconomic reforms, which have the effect of causing a reduction in the volatility of the cycles. According to Sosa (2008), with the induced stability, the importance of external shocks related to the sector gained relevance in explaining the internal fluctuations.

Since the 1970's the Mexican exports had been reduced and terms of trade were not favorable to the country. But, the transactions with neighboring countries run over the trade agreement under NAFTA. Only with the U.S. the commerce that was 90 billion dollars in 1993 came to 365 billion in 2007. This increased trade integration may have helped reduce the volatility of the product in Mexico, and bring the country to the same characteristics of cyclical behavior of the U.S. economy. This scenario is mentioned by Sosa (2008), which identifies the importance of the shocks of demand in the U.S. to determine the cycles in Mexico, especially in the post trade agreement. This relationship is strongest in the industrial sector, since much of the Mexican exports of intermediate goods is to serve the industry in the U.S.. Therefore, variations observed in the U.S. industrial production are important sources of shock to the fluctuation in Mexican production.

The results of Santos (2002) for the period of 1972 to 1999 indicate that the country has experienced recessions more pronounced than expansions with shorter periods. The Mexican economy has moved from an expansion to a recession in the years 1982, 1985-1986 and 1994. On the other hand the movement opposed to the expansion occurred during the recession years 1983, 1986 and 1995. These events were captured by the univariate model, see table 1 . In regime 1 the economy has a negative high average growth rate of $-5.46 \%$. This characterizes the period of pronounced shrinkage. But we can see, like in Santos (2002) that the difference between them is the time duration of the phases. When the country is in regime 2 the average rate of expansion is around $5.16 \%$. Moreover, the duration is longer than regime 1 namely, the Mexican economy is growing longer than in recession. According to Santos (2002), the asymmetry in terms of magnitude of growth and recession is one of the characteristics of Mexican cycle, unlike the Chilean economy, which has values diametrically opposed in terms of switching.

The matrix of transition indicates that while being in recessions, there is a greater likelihood of switching regimes. However, if the economy is growing, the probability of staying in this state is more significant, as can be seen in the table 1 . These results reinforce the proposal by Santos (2002) where, although the parameter of the recessionary period is more pronounced, its duration is very short, and that growth in Mexico has been stable over this period.

Individual analysis of this section indicated the presence of several stylized facts of business 
cycle in each country, such as asymmetry, duration and intensity. However, when analyzing the probabilities of the regimes, recession and the expansion, we see that the economies have a very similar behavior. Concerning the duration, this was with different values. One likely reason for this behavior can be credited to the dynamic growth of each country.

\section{MULTIVARIATE MODELS}

An interesting point about the economic cycles is to identify a common link between different economies. Under this hypothesis, it is expected that a multivariate switching model will produce better results than univariate model. Furthermore, the multivariate model can produce additional information to better observe the characteristics of economic cycles.

A multivariate model can be done from the estimation of the vector of annual growth rate $\Delta y_{t}=\left[\Delta y_{t}^{A R G}, \Delta y_{t}^{B R}, \Delta y_{t}^{C H}, \Delta y_{t}^{M E X}\right]^{\prime}$. The basic premise that leads to combine modeling lies in the fact that the countries have been selected subject to the same dynamics of common external shocks over the period of study. Under the presence of common shocks, as explained Kose et al. (2003), economies tend to converge to a uniform cyclical pattern between them. If this correlation is perfect, the mechanism of propagation of the pulses should lead to a common movement.

Table 2: Multivariate models

\begin{tabular}{llllll}
$c_{1}$ & $c_{2}$ & $p_{11}$ & $p_{22}$ & $D_{1}$ & $D_{2}$ \\
\hline
\end{tabular}

$\begin{array}{lllllll}\text { Argentina } & -2.0334 & 5.9284 & 0.574 & 0.709 & 2.35 & 3.44\end{array}$

$\begin{array}{lllllll}\text { Brazil } & 2.7901 & 5.9719 & - & - & - & - \\ \text { Chile } & 3.1034 & 4.4585 & - & - & - & - \\ \text { Mexico } & 2.8946 & 5.7187 & - & - & - & -\end{array}$

Note: $D_{1}$ and $D_{2}$ are cycle durations.

As with univariate models, we use Akaike (AIC), Hanna-Quinn (HQ) and Schwartz (SC) to select the multivariate models. After choosing the number of lags the Likelihood Ratio is used to verify the significance of the restrictions starting with four lags and cutting them up with each step. It was also considered switching in average, intercept and variance. All of them consider the possibility of $k>2$. Although structures can be estimated with more than two states, there is a significant increase in the number of parameters of the model, and convergence becomes more difficult.

Elsewhere, the likelihood ratio test selects the VAR without lags for all variables with $\chi_{(14)}^{2}=0,000$ like the linear one. The results from criteria used here selects the structure with switching in intercept and heteroskedasticity $\operatorname{MSIH}(2)$ $\operatorname{VAR}(0)$, and is shown in table 2 . So, there is an asymmetry in the rate of growth of the four countries in the multivariate model. Argentina had the highest rate of recession, about $-2.03 \%$ per year. We see that the transition matrix is irreducible and ergodic.

Unlike the univariate estimates, which had different transitions between states (recessions and expansions), the multivariate model presents defined states with low possibility of transition between them, see $\left(p_{21}, p_{12}\right)$ values. This result indicates that if the four countries are in recession, the possibility of growing together is less than other one. The reverse analysis is also valid. However, the probability of the four countries stay in a regime of growth $\left(p_{22}>p_{12}\right)$ is greater than the probability of transition. Moreover, $p_{22}>p_{11}$ indicates that, with growth in all four countries, there is a greater likelihood of remaining well.

Although the periods of recessions have shown how deep, like in Argentina, they are approximately half of the periods of expansion. The average duration of a regime of recession for all countries together is 2.3 years. For the period of expansion, the duration is 3.4 years. Figure 6 shows the development of combined probabilities of recession in the region. We use $p_{1}>0,5$ to define periods of recession. 
Figure 6: Smooth probability of regime $1 \mathrm{MSIH}(2)-$

$-\operatorname{VAR}(0)$

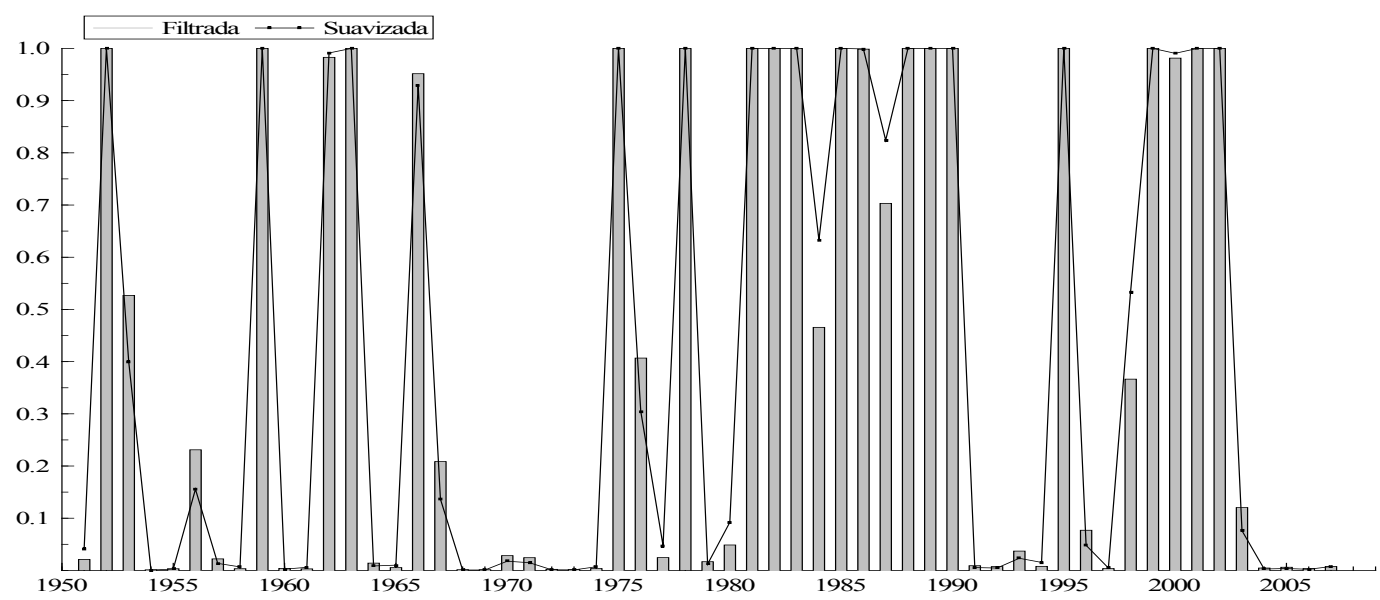

Table 3 shows the dates of the common economic cycles to four countries for both peaks and troughs. According to the theory of economic cycles, a recession is characterized by the period between the peak and troughs. In this case, we can define five periods of recession in the joint region: 1958-1959, which can be associated with political change, 1974-1975 and 1980-1981, both related to the two oil shocks and the international economic recession, and finally, the period between 1997-1998, where there were financial crises in Asia and Russia. to the volatility of revenue, was pro-cyclical. Such behavior is widespread throughout the 1960's, resulting in high rates of inflation. Both Brazil and Argentina have just experienced a high inflation phase in the period of 1980 to 1995 , as well as Chile, which, over the 70's also experienced a period of high inflation.

One aspect of the economic history of the region is that inflation has been in several years an anti-ciclical factor. This was an opposite behavior to that observed in developed economies. Therefore, in this case, the trade off of the Phillips

Table 3: Dates of common business cycles

\begin{tabular}{lllllll}
\hline Peaks & 19551958 & 19601974 & 19761980 & 19911994 & 19961997 & 20032007 \\
\hline Troughs & 19591959 & 19751975 & 19811990 & 19951995 & 19982002 & \\
\hline
\end{tabular}

The business cycles in Latin America post1960 were very volatile. They remained with this feature as both during and after the oil crisis. This occurred in aggregate economic volatility, as interest rates, investment and consumption. This would generate a fluctuating behavior of the economy. However, from the beginning of the 1990's the process of globalization has created conditions of complementarity reducing the volatility of economic aggregates. However, this is still higher than that seen in developed countries, as well as for other developing in Asia; see Aiolfi et al. (2006).

The high expense of the public sector for years in several countries of the region is a common factor that helps explain the high volatility of the product. For all four countries and in all sub periods analyzed in this article, the level of actual expenditure made by governments, related curve did not occur. This feature of inflation can be credited to the rigidity of short-term nominal wages, a variable common to the four countries.

We can also observe that the terms of trade behave as a pro-cyclical variable. A feature common to the four countries of the region is that all of them are exporters of commodities. This plays an important role in the balance of external accounts. Brazil and Mexico established industrial policies and consolidated a diversified economy. On the one hand, this policy contributed to a different dynamic for the product. But that did not prevent external shocks from producing strong fluctuations in these economies.

Statistical tests show a dynamic causality between the countries. This raises the idea to investigate binary relations. For this, formulations were made between Argentina and Brazil, Argentina and 
Chile, Argentina and Mexico. Based on the criteria of Akaike (AIC), Hanna-Quinn (HQ) and Schwartz (SC), we use the model MSM(2)-VAR(0) for Argentina and Brazil. To the relationship between Chile and Argentina we chosen MSIH(2)-VAR(0). And MSM(2)-AR(1) to the analysis of Argentina and Mexico. Table 4 presents these results.
Argentina and Chile. The test indicated a causal relationship between Argentina and Chile. The results of the bivariate model of switching regime indicate an improvement in average growth rates when the two economies are in recession. However, it has a higher volatility. This characteristic indicates that the impact of recessions is

Table 4: Bivariate models

\begin{tabular}{ccccc}
\hline & Argentina & Brazil & Chile & Mexico \\
\hline \multirow{2}{*}{ Argentina } & & Arg. $=5.49$ & Ch. $=4.9043$ & Arg. $=3.270$ \\
& & Br $=3.4859$ & Arg. $=6.2735$ & Mex. $=5.710$ \\
Brazil & Arg $=-3.9234$ & & & \\
& Br. $=-2.4263$ & & & \\
Chile & Arg. $=-1.9594$ & & \\
& Ch. $=2.6195$ & & & \\
Mexico & Arg. $=-1.80$ & & & \\
& Méx. $=-3.53$ & & & \\
Note: Column are the values of $\mu_{1}$ and in row $\mu_{2}$. & & & \\
\end{tabular}

Argentina and Brazil. The influence of Argentina over Brazil becomes small when diluted in a horizon of time. This can be confirmed from $\mu_{1}$ and $\mu_{2}$ to Brazil. In this case, in a recession the average growth rate is much lower in Argentina $-3.9 \%$ per year, against $-2.42 \%$ for Brazil. In a regime of growth, this relationship is inverted and the economy of Argentina has a dynamic more intense with average rate of $5.49 \%$ per annum, against $3.48 \%$ for Brazil.

The matrix of probability transition indicates that, if both economies are in recession, there is a high chance of going to grow. This may be reflecting the high commercial connection that exists between the two countries and the correlation of external shocks and macroeconomic policies implemented during the period analyzed.

However, if the two economies are in a regime of growth, $p_{22}>p_{21}$, likely to remain in this regime is more significant than both entering recession. Again, this is a result that shows the complementarity in these two countries and the gains of scale generated by international economic integration, particularly in the Mercosur agreement. The stationary probabilities of growing are greater than to the common recession, as $p_{22}=0,70$ points. Finally, periods of growth have durations that are more than twice the durations of recessions, four years each. This longer duration indicates the existence of an interesting dynamic of growth, even before all the external shocks and problems in the current accounts. more pronounced than the effect of an expansion of GDP, which may be influenced by the strong fall in GDP occurred in the Chilean economy in 1974 and 1982. Anyway, estimates of the bivariate model indicate that in the recessive periods Chilean economy grows about $2.6 \%$ a year, while Argentina's economy would fall to $-1.95 \%$. The asymmetry in the business cycles remains when considering the regime of growth. In this case, Argentina is expanding at an average rate of $6.2 \%$ per year while Chile only $4.9 \%$. These results are higher than the univariate estimates.

Estimates of the transition probability matrix indicate that if the two economies are in a regime of recession, the probability of moving to a regime of growth is lower, as can be seen in $p_{11}>p_{12}$. Because of this, a jointly recession would be more difficult to solve. Elsewhere, a common scenario for growth presents strong position to maintain, $p_{22}>p_{21}$. It also shows that the stationary probabilities of the economies growing together are greater than to be in recession. The periods of recession lasts on average 2.05 years and 2.65 years of growth.

Argentina and Mexico. The tests indicate an autoregressive relationship from Argentina to the economy of Mexico. The bivariate model results in average growth rates during periods of recessions different from the univariate and multivariate models. In the case of Mexico we see $-5.46 \%$ in the univariate and $-3.53 \%$ to bivariate one. The same behavior can be observed in the bivariate 
comparison of the multivariate model. The recessions become more pronounced for Mexico, with average rate of $-3.53 \%$ per year compared to $-1.8 \%$ for Argentina. Since the variance of the model for the regime 1 is positive and smaller than in regime 2 , we can infer that the recessive shocks produce more instability than periods of growth.

The economy of Mexico has also higher rates in the regime of growth, $5.71 \%$ against $3.27 \%$ for Argentina. The autoregressive dynamics indicate a lag of one year to Argentina's impacts on Mexico. This may be related to trade agreements and export contracts between the two countries, especially after the 1990's. The implication is that the effects of growth need a certain time to be absorbed by the country.

The matrix of probability transition indicates that $p_{12}>p_{11}$. Thus, if the economies are in recession, there is a greater possibility of the two countries leave this regime. Also, the likelihood of a joint expansion $p_{22}>p_{21}$ is higher. These results confirm the idea that both countries had a more pronounced growth performance over the period analyzed. The joint probability of recession is 0.1482 , with the average duration of two years. The likelihood that both economies are growing is 0.8518 with a mean interval of more than eleven years.

Several stylized facts have been found in the bivariate and multivariate results and prove the existence of co-movement between the four economies examined here. From the first oil shock both, Argentina as Mexico began to face a period of instability in their regimes of growth. In this case the recessions were more forceful. Furthermore, the constant internal imbalances added to international instability produced a greater number of recessions in the analyzed period.

These constant changes in the institutional and political scenario in Latin America may have contributed to increasing volatility of the product. The growth dynamics of the region were also very sensitive to external shocks. Other important sources of asymmetry in the business cycle may be the lack of economic policy, the erratic behavior of fixed investment, high public spending and the terms of trade. However, the data suggest that even before the intensification of economic globalization in the 1990's, fluctuations of the product showed greater synchrony. This fact reinforces the hypothesis of the existence of a common regional factor.

\section{FINAL COMMENTS}

This paper uses univariate and multivariate Markov switching models for four Latin American countries between 1950 and 2007. The results show that a different dynamic of growth between countries. Argentina has had small changes in parameters in univariate and multivariate models, especially for those who represent the average growth rate of the economy in recessive periods. In the univariate model we see $-3.74 \%$ and to multivariate $-2.03 \%$. In the regime of expansion the values ranging between $5.60 \%$ and $5.92 \%$ respectively. Note that there was an improvement in the parameters when these were calculated in the multivariate model, which indicates the existence of a co-movement between countries.

The recessions in Brazil ranging from a $2.45 \%$ average in the univariate model to $2.79 \%$ in the multivariate, but this remains positive. Periods of expansion in the parameter that measures the average growth rate declined from $6.72 \%$ in univariate model to $5.97 \%$ in the multivariate. Moreover, tests indicate that there is not a strong relationship between Brazilian economy and others countries analyzed.

The results for Chile showed greater symmetry in the cycle with other countries. The parameter that indicates the recessions in the univariate model indicated that these were high, with a rate of $-14.89 \%$ per year. In multivariate models the recessions are less intense, with rate of $3.10 \%$ per year. The expansions in the univariate model were $3.65 \%$ and in the multivariate model of $3.10 \%$. One reason for this difference between the two regimes is due to the difference in the models specified. While in the univariate we use a switching in intercepting with one lag, in the multivariate model this is in the mean and heteroskedastic.

In recessive periods GDP in Mexico had an average rate of $-5.46 \%$ in the univariate model and $2.89 \%$ in the multivariate. In this regime the expansion rate is $2.81 \%$ in the univariate and $5.71 \%$ in multivariate. One reason for this behavior may be the growing influence of the U.S. economy in the country, especially after the second half of the 1990's. This greater integration may have smoothed the business cycle of the country.

The causality test shows a bivariate relationship between the countries. The parameter model between Argentina and Brazil changed little. Between Chile and Argentina, the parameters of the bivariate model are superior to univariate and multivariate. The joint analysis between Argentina 
and Mexico helps smooth the business cycle for the economy of Mexico. However, in periods of expansion, there is little change in rate between the bivariate and multivariate model.

The results indicate that the nature of macroeconomic shocks have different magnitude and dynamic in the analysis. However, there is evidence of common movement among the four countries in the long term. It was also possible to verify the existence of movements of adjustment to exogenous shocks. These have caused disturbances in the dynamics of growth. In this case the magnitude and speed of adjustment is related to the structure of each economy.

\section{REFERENCES}

AIOLFI, M.; CATÃO, L.; TIMMERMANN, A. Common Factors in Latin America's Business Cycles. Nova York: IMF Working Paper, 2006.

BÖWER, U.; GUILLEMINEAU, C. Determinants of Business Cycle Syncronisation Across Euro Area Countries. ECB working paper, n. 587, 2006.

BRY, G.; BOSCHAN, C. Cyclical Analysis of Time Series: Selected Procedures and Computer Programs. NBER Technical Paper, 20, 1971.

BURNS, A.; MITCHELL, W. Measuring Business Cycles. New York: National Bureau of Economic Research, 1946.

CHAUVET, M. An Econometric Characterization of Business Cycle Dynamics with Factor Structure and Regime Switching. International Economic Review, Philadelphia, v. 39, n. 4, p. 969-996, 1998.

CHAUVET, M.; MORAIS, I. A. C. Predicting Recessions in Brazil. Rio de Janeiro: FGV/EGPE, 2008.

CHAUVET, M.; POTTER, S. Coincident and Leading Indicators of the Stock Market. Journal of Empirical Finance, v. 7, p. 87-111, 2000.

\section{CLEMENTS, M. P.; KROLZIG, H-M. Business}

Cycle Asymmetries: Characterization and Testing Based on Markov-Switching Autoregressions. Warwick: University of Warwick/Department of Economics, 1999.

CLEMENTS, M. P.; KROLZIG, H-M. Modeling
Business Cycle Features Using Switching Regime Models. Oxford: University of Oxford/Department of Economics, 2001.

CORREA, A. S. Diferenças e Semelhanças entre Países da América Latina: Uma Análise de Markov Switching para os Ciclos Econômicos de Brasil e Argentina. Texto para Discussão Banco Central do Brasil, n.80, 2003.

CORREA, A.S.; HILBRECHT, R. O. Ciclos Internacionais de Negócios: Uma Análise de Mudança de Regime Markoviano para Brasil, Argentina Estados Unidos. Texto para Discussão Banco Central do Brasil, n.88, 2004.

DIEBOLD, F. X.; LEE, J. H.; WEINBACH, G. C. Regime Switching with Time-varying Transition Probabilities. In: HARGREAVES, G. (ed.). Nonstationary Time Series Analysis and Cointegration. Oxford: Oxford University Press, 1994.

FILARDO, A. J. Business-cycle Phases and their Transitional Dynamics. Journal of Business and Economic Statistics, Washington, v. 12, p. 299-308, 1994.

FILARDO, A. J.; GORDON, S. F. Business-cycle Durations. Journal of Econometrics, North-Holland, v.85, p.99-123, 1998.

GARCIA, R. Asymptotic Null Distribution of the Likelihood Ratio Test in Markov Switching Models. International Economic Review, Philadelphia v. 39, n. 3, p. 763-788, 1998.

HAMILTON, J. D. A New Approach To the Economic Analysis of Nonstationary Time Series and the Business Cycle. Econometrica, Princeton, v. 57, p. 357-384, 1989.

HAMILTON, J. D. A New Approach to the Economic Analysis Of Nonstationary Time Series and the Business Cycle. Econometrica, Princeton, v. 57, p. 357-384, 1989.

HAMILTON, J. D. A Quasi-Bayesian Approach to Estimating Parameters for Mixtures of Normal Distributions. Journal of Business and Economic Statistics, Washington, v. 9, p. 27-39, 1991.

HAMILTON, J. D. Specification Testing in MarkovSwitching Time Series Models. Journal of Econometrics, North-Holland, v. 70, p. 127-157, 1996. 
HAMILTON, J. D.; SUSMEL, R. Autoregressive Conditional Heteroskedasticity and Changes in Regime. Journal of Econometrics, North-Holland, v. 64, p. 307-333, 1994.

HANSEN, B. E. The Likelihood Ratio Test Under Non-Standard Conditions: Testing the Markov Switching Model of GNP. Journal of Applied Econometrics, Cambridge, n.7, p.61-82, 1992.

KIM, C-J; NELSON, C. R. State-Space Models with Regime Switching - Classical and Gibbs-Sampling Approaches with Apllications. 2. ed. Massachusetts: MIT Press, 2000.

KOSE, A.; OTROK, C.; WHITEMAN, C. H. International Business Cycles: World, Region, and Country-specific Factors. The American Economic Review, ed. 93, v.4, 2003.

KOSE, A.; OTROK, C.; WHITEMAN, C. H. Understanding the Evolution of World Business Cycles. IMF Working Paper, 2005.

KOSE, M. A.; OTROK, C.; PRASAD, E. S. Global Business Cycles: Convergence or Decoupling? NBER working paper, Cambridge, n. 14292, 2008.

KROLZIG, H-M. International Business Cycles: Regime Shifts in the Stochastic Process of Economic Growth. Applied Economics Discussion Paper University of Oxford, n.194, 1997.

KROLZIG, H-M. Statistical Analysis of Cointegrated VAR Processes with Markovian Regime Shifts. Discussion Paper Humboldt Universität zu Berlin, Berlin, n. 25, 1996.

KROLZIG, H-M; MARCELLINO, M.; MIZON, G. E. A Markov-Switching Vector-equilibrium Correction Model of the UK Labour Market. Oxford Working Paper, 2000.

MENDOZA, E., The Terms of Trade, the Real Exchange Rate, and Economic Fluctuations. International Economic Review, Philadelphia, n. 36, p. 101-137, 1995.

SANTOS, A.O., Are Mexican Business Cycles Asymmetrical? IMF Working Paper, 2002.

SHIN, K.; WANG, Y. Trade Integration an Business Cycle Synchronization in East Asia. Asian Economic Papers, vol. 2, p. 1-20, 2003.
SIMONOVSKA, I.; SÖDERLING, L.; TIMMERMANN, A. Business Cycle Accounting for Chile. IMF Working Paper, 2008.

SOSA, M. S. External Shocks and Business Cycle Fluctuations in Mexico: How Important are U.S.

Factors? IMF Working Paper, 2008.

STOCK, J. H.; WATSON, M. H. A New Approach to Leading Economic Indicators. Haward University Working Paper, 1988.

STOCK, J. H.; WATSON, M. H. A Probability Model of the Coincident Economic Indicators. In: LAHIRI, K.; MOORE, G. H. Leading Economic Indicator: New Approaches and Forecasting Records. Cambridge: Cambridge University Press, 1991.

STOCK, J. H.; WATSON, M. H. A Procedure for Predicting Recessions with Leading Economic Indicators: Econometric Issues and Recent Experience. In: STOCK, J. H.; WATSON, M. W. Business Cycles, Indicators and Forecasting. Chicago: University of Chicago, 1993.

STOCK, J. H.; WATSON, M. H. New Indexes of Coincident and Leading Economic Indicators. In: BLANCHARD O.; FISCHER, S. (eds.). NBER Macroeconomics Annual. Massachusetts: MIT Press, 1989.

WORLDBANK. Base de Dados Estatísticos. Disponível em: http://web.worldbank.org/WBSITE/ EXTERNAL/DATASTATISTICS/0,,contentMDK :20535285\%7EmenuPK:1192694\%7EpagePK:6413 3150\%7EpiPK:64133175\%7EtheSitePK:239419,00. html Acesso em: 17 maio 2008.

ZARNOWITZ, V. Business Cycles: Theory, History, Indicators, and Forecasting. Chicago: The University of Chicago Press, 1996. 